\title{
Phase behavior of reverse poloxamers and poloxamines in water
}

\author{
Eneko Larrañeta, José Ramón Isasi* \\ Departamento de Química y Edafología, Facultad de Ciencias, \\ Universidad de Navarra, 31080Pamplona, Navarra, Spain
}

This document is the unedited Author's version of a Submitted Work that was subsequently accepted for publication in Langmuir, copyright (C) American Chemical Society after peer review. To access the final edited and published work see http://pubs.acs.org/doi/abs/10.1021/la304245p

* Corresponding author. Tel.: +34-948-425600; fax: +34-948-425740.

E-mail address: jrisasi@unav.es (J.R. Isasi). 
ABSTRACT: The phase behavior of two types of poly(ethylene oxide)/ poly(propylene oxide) (PEO/PPO) copolymers in aqueous solutions was studied by light scattering, viscometry and infrared spectroscopy. Both the reverse poloxamer (Pluronic 10R5) and the star type poloxamine (Tetronic 90R4) have practically the same PEO/PPO ratio with their hydrophobic blocks (PPO) located in the outer part. The temperature-composition phase diagrams show that both $10 \mathrm{R} 5$ and $90 \mathrm{R} 4$ tend to form aggregates in water. Up to four different phases can be detected in the case of Tetronic 90R4 for each temperature: unimers, random networks, micellar networks and macrophase separation. Viscometric and infrared measurements complemented the results obtained by light scattering and visual inspection.

Keywords: Poloxamer; poloxamine; phase behavior; viscometry

\section{INTRODUCTION}

Amphiphilic molecules such as PEO/PPO linear block copolymers, can exhibit interesting properties when dissolved in water. Because of their emulsifying, dispersing or surfactant properties they are frequently used in different industries such as metallurgy and petroleum industry. Nevertheless, their association properties make them applicable in many other fields such as cosmetics, textile industry, and pharmaceutical formulations. The triblock copolymers, synthesized and distributed by BASF under the name of Pluronic ${ }^{\circledR}$, can be prepared with different molecular weights and PEO/PPO ratios. The most important property of Pluronic is its ability to form micelles or other self-assembled structures in water under certain conditions. ${ }^{1-3}$ 
Pluronics are linear copolymers formed by three different blocks: two outer PEO blocks of the same length and an inner PPO block. The PPO block presents a hydrophobic behavior while PEO blocks possess a hydrophilic character.

Reverse Pluronics (Pluronic R®) are also PEO/PPO linear block copolymers, but the configuration of the blocks is changed: PPO-PEO-PPO (Figure 1a). Since the hydrophobic blocks are now in the outer portion of the chains, this fact leads to a different behavior in water. These Pluronic R copolymers have been considerably less studied although within the last years they are attracting more interest. Several applications and their thermodynamic properties in water have been recently reported. ${ }^{4-6}$ Besides Pluronics BASF synthesize another type of PEO/PPO block copolymers called Tetronic. These block copolymers are four-arm star molecules containing eight blocks of PEO and PPO, both in the standard and the reverse disposition (Figure 1b). Tetronic $\mathrm{R}$ molecules have been scarcely studied. ${ }^{7,8}$ Due to the recent advances in polymer chemistry such as atom transfer radical polymerization, the tailor-made synthesis of various architectures has emerged. Branched polymers, star polymers and dendrimers show different solutions properties to those corresponding to their analogous linear architectures: their hydrodynamic properties are quite different and the network formation to show a hydrogel behavior is feasible. ${ }^{9}$

a)
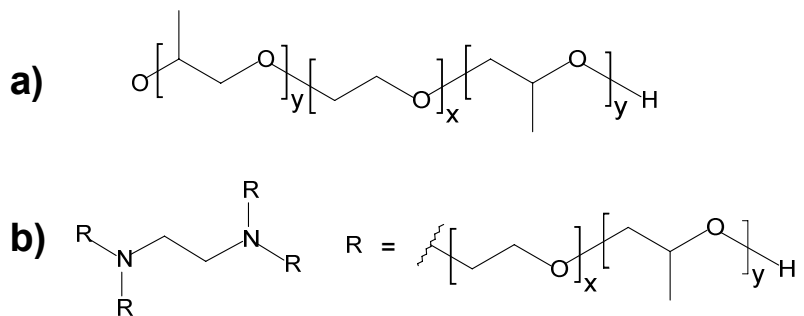

Figure 1. Chemical structure of a Pluronic R (a) and a Tetronic R (b) 
Water is a selective solvent for the ethylene oxide blocks in PEO/PPO copolymers. For the regular Pluronic configuration, spherical aggregates are easily formed. PPO blocks are placed inside the core protected from the solvent by the outer PEO blocks. These blocks are located in the surface of the sphere, in contact with the solvent. Besides, PEO-PPO-PEO polymers can form other types of structures such as rodlike or layered forms depending on their molecular architecture (PEO-PPO block length ratio) and temperature. ${ }^{10-12}$

Reverse Pluronic and Tetronic copolymers are also capable of forming aggregates in aqueous solutions. Nevertheless, due to the selective nature of water, the aggregates formed are of a different type. While Pluronic copolymers tend to form micelles in water (Figure 2a), micellization in reverse Pluronics is a less favorable process as it has been reported ${ }^{13}$. Therefore, PPO-PEO-PPO chains must form another type of aggregate that can be more suitable for them. In some cases Pluronic R copolymers can form different aggregates. For instance, flower type micelles are spherical aggregates with the PEO block at the surface and the PPO blocks forming the core (Figure 2b). Another option is to form either a micellar network or a random network (Figure 2c). ${ }^{7,14,15}$ In fact, for ABA block copolymers it is best that the A-blocks are incorporated in different domains, because in that case the entropy of the B-block is not lowered too much, as would be the case when forming a loop, by backfolding to the same domain. Thus a three-dimensional network will be formed: the A-block domains behave as multifunctional crosslinks and the flexible B-blocks as network chains. Random networks are formed when the concentration is not high enough to form micellar associations but there are interactions between the A-blocks. ${ }^{16}$ 
(a)

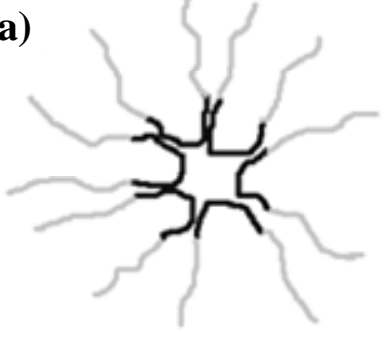

(b)

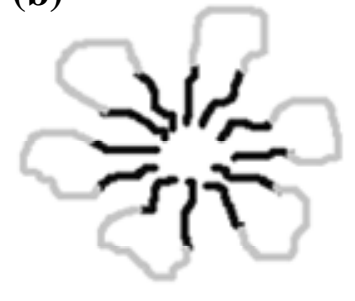

(c)

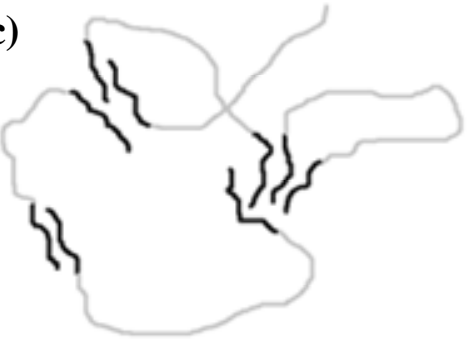

Figure 2. (a) Normal micelle (b) Reverse or flower type micelle (c) Random network

As indicated above, only a few studies have been published on the reverse type Pluronic copolymers and even fewer investigations regarding reverse Tetronics. The present work focuses on the aggregation behavior of two reverse PEO/PPO copolymers in water, Pluronic $10 \mathrm{R} 5$ and Tetronic $90 \mathrm{R} 4$. The aims of this study were to evaluate the phase behavior both by light scattering and viscometry, and to investigate the structure of the aggregates formed by these reverse type block copolymers.

\section{EXPERIMENTAL SECTION}

Materials. Pluronic 10R5 and Tetronic 90R4 were a gift from BASF Corp. They were used as received without further purifications. Pluronic 10R5 is a viscous (440 cP at $25^{\circ} \mathrm{C}$ ) colourless liquid with a nominal molecular weight of $1950 \mathrm{~g} / \mathrm{mol}$, as stated by the manufacturer. The chemical formula given by the manufacturer $\mathrm{PO}_{8} \mathrm{EO}_{22} \mathrm{PO}_{8}$ was corroborated by ${ }^{1} \mathrm{H}-\mathrm{NMR}$ (Bruker DPX 300 at $298 \mathrm{~K}$ ). Tetronic $90 \mathrm{R} 4$ is yellow liquid with a higher viscosity $\left(3870 \mathrm{cP}\right.$ at $\left.25^{\circ} \mathrm{C}\right)$. The molecular weight given by the manufacturer is $6900 \mathrm{~g} / \mathrm{mol}$. Its block composition was determined by ${ }^{1} \mathrm{H}-\mathrm{NMR}$ yielding a result of $\mathrm{PO}_{16} \mathrm{EO}_{18}$ per arm (Figure 1b). 
Phase diagrams. The phase diagrams of the water suspensions were obtained by two different techniques: direct observation of the cloud points and dynamic light scattering. The latter was also useful to obtain the hydrodynamic radii of the species at different temperatures. In the case of dilute solutions, it was not possible to ascertain the cloud points by visual inspection. Direct observation measurements are not reliable for copolymer concentrations below $10 \%$.

Different aqueous mixtures were prepared in the concentration range between 0 and $80 \%(\mathrm{w} / \mathrm{w})$ for both copolymers. The suspensions were prepared in $10 \mathrm{~mL}$ vials using deionised water and placed into a thermostatic bath. The phase behavior was studied between 20 and $60^{\circ} \mathrm{C}\left( \pm 0.1^{\circ} \mathrm{C}\right)$ for $10 \mathrm{R} 5$ and between 10 and $60^{\circ} \mathrm{C}$ for $90 \mathrm{R} 4$. Samples were kept for at least 10 minutes at a constant temperature, to assure equilibrium was reached, prior to their analysis. In some cases, cloud point determinations by direct observation were difficult, and a laser beam was used in order to ascertain the turbidity in the samples. In order to discard the possible effect of impurities on the cloud point determinations, additional experiments were carried out: once turbidity was obtained by heating the sample (ca. $40-45^{\circ} \mathrm{C}$ in the case of $20 \%$ Pluronic, and ca. $30^{\circ} \mathrm{C}$ for $20 \%$ Tetronic) the solutions were filtered using $0.45 \mu \mathrm{m}$ pore size nylon syringe filters. After filtration, the solutions remained clear, but after a while they started to become turbid again.

Dynamic Light scattering. DLS measurements were performed at a scattering angle of $90^{\circ}$ using a DynaPro-MS/X photon correlation spectrometer equipped with a 248 channel multi-tau correlator and a Peltier effect temperature unit. The wavelength of the laser was $852.2 \mathrm{~nm}$. The size distribution was obtained from the intensity autocorrelation function by regularization analysis, implemented in the Dynamics ${ }^{\mathrm{TM}}$ software package. The hydrodynamic radii were calculated from the diffusion 
coefficients by means of the Stokes-Einstein equation. The mass distributions were calculated using the Regularization method, implemented in the software.

Copolymer suspensions of concentrations ranging between 1 and $40 \%(\mathrm{w} / \mathrm{w})$ were measured by averaging 200 scans. The temperatures analyzed for 10R5 were between 25 and $50^{\circ} \mathrm{C}\left( \pm 0.1^{\circ} \mathrm{C}\right)$ and they ranged between 10 and $50^{\circ} \mathrm{C}$ in the case of $90 \mathrm{R} 4$. Fivedegree intervals were considered sufficient (except for 10R5 diluted mixtures) to ascertain the scattering behavior and the radii variations as a function of the temperature. Aggregation numbers were estimated from the hydrodynamic radii using a branched polymer model in the Dynamics ${ }^{\mathrm{TM}}$ software (molecular weights for the aggregates are calculated using this model, and the ratio between these and the molecular weight of the unimers are the estimated aggregation numbers). All samples were previously filtered through $0.45 \mu \mathrm{m}$ pore size nylon syringe filters.

Viscosity measurements. Capillary viscosities and rotational viscosities were measured for different concentration ranges. A capillary Cannon-Fenske viscometer was used to obtain the intrinsic viscosity of dilute aqueous solutions of 90R4 and 10R5. The intrinsic viscosities between 1 and $10 \mathrm{~g} / \mathrm{dL}$ were calculated using the Huggins equation from the viscometer flow times. Time measurements were performed in triplicate at $25^{\circ} \mathrm{C}\left( \pm 0.1^{\circ} \mathrm{C}\right)$ in a thermostatic bath. Assuming the spherical model, the hydrodynamic radius $\left(\mathrm{R}_{\eta}\right)$ can be estimated from the equation derived from the hydrodynamic model of Kirwood-Riseman. ${ }^{13}$

$$
\mathrm{R}_{\eta}=\left([\eta] \cdot 3 \mathrm{M} / 10 \cdot \pi \cdot \mathrm{N}_{\mathrm{A}}\right)^{1 / 3}
$$

where [ $\eta]$ is the intrinsic viscosity of the sample, $M$ is the molecular weight of the polymer and $\mathrm{N}_{\mathrm{A}}$ is the Avogadro constant.

Rotational viscometry was used for more concentrate samples. Pluronic 10R5 concentrations were 20, 30 and $40 \%(\mathrm{w} / \mathrm{w})$. In the case of Tetronic $90 \mathrm{R} 4,20$ and $30 \%$ 
(w/w) mixtures were measured. A Haake Viscotester 550 with a cylindrical rotor MV1 (inner diameter $20.04 \mathrm{~mm}$; outer diameter $21 \mathrm{~mm}$; height $60 \mathrm{~mm}$ ) equipped with a thermostatic bath Thermo Phoenix II was used. Measurements were carried out using a constant shear rate, $1000 \mathrm{~s}^{-1}$, at temperatures ranging between 20 and $40^{\circ} \mathrm{C}$ for Pluronic $10 \mathrm{R} 5$, and between $15-50^{\circ} \mathrm{C}$ in the case of Tetronic $90 \mathrm{R} 4$, after at least 10 minutes of temperature stabilization.

Fourier transform infrared (FTIR) spectroscopy. Spectra were collected with a Nicolet-FTIR Avatar 360 spectrometer, using a MKII Golden Gate ATR device with a resolution of $4 \mathrm{~cm}^{-1}$. The spectrum obtained was an average of 32 scans and they were analyzed using OMNIC E.S.P. software. The spectrometer was coupled to a Specac heated Golden Gate temperature controller $\left( \pm 1^{\circ} \mathrm{C}\right)$. A volatiles cover was placed above the liquid samples to avoid the evaporation of water. Temperatures between 21 and ca. $60^{\circ} \mathrm{C}$ were measured using 1 min equilibration times before taking the spectra.

\section{RESULTS AND DISCUSSION}

Pluronic 10R5 + water. Figure 3 shows the phase diagram of the system 10R5/water. This reverse poloxamer is water soluble in the whole concentration range at room temperature. Both direct observation and light scattering yield practically the same results below $40 \%(\mathrm{w} / \mathrm{w})$. Beyond this point, light scattering measurements were not possible because the mixtures presented homogeneity and viscosity problems. The cloud points detected by visual inspection correspond to a large increase in the scattered intensity as measured by the DLS spectrometer (Figure 4). For concentrations between $30 \%$ and $50 \%$, three regions have been observed (Figure 3). Region I, at low temperatures corresponds to clear solutions. In region II, the solutions become turbid. 
When the temperature is increased, the mixtures are again transparent (region III). Above $50 \%(\mathrm{w} / \mathrm{w})$ this behavior is not observed, and the samples remain clear in the studied temperature range (i.e. up to $60^{\circ} \mathrm{C}$ ).

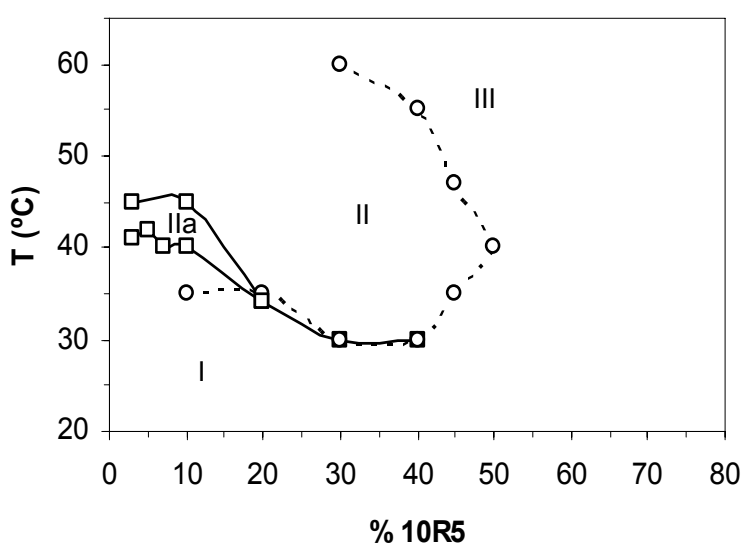

Figure 3. Phase diagrams of Pluronic 10R5 in water obtained by ( $\square$ ) DLS and (०) direct observation. Region I: unimers (transparent); region II: random network (turbid); region IIa: small aggregates (transparent); region III: micellar networks (transparent)

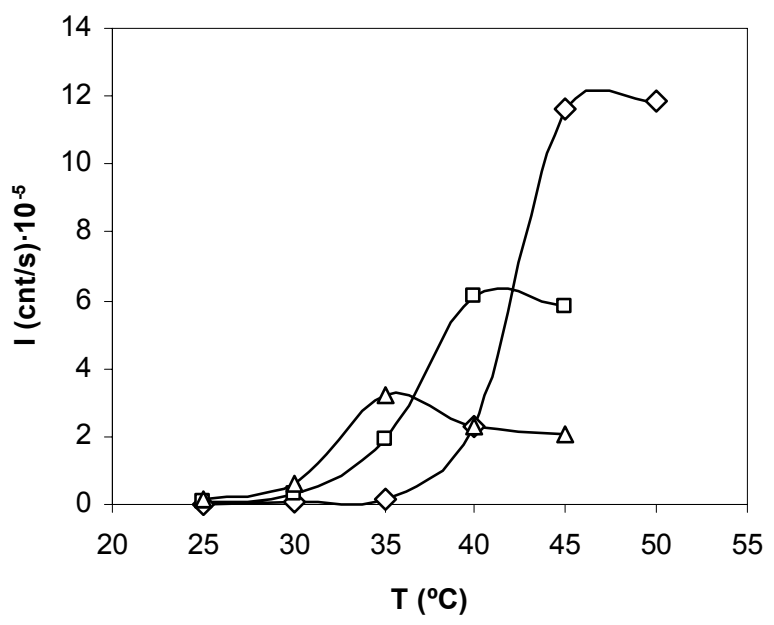

Figure 4. Variations of scattered intensity (wavelength $852.2 \mathrm{~nm}$; scattering angle $90^{\circ}$ ) for different 10R5 semidiluted solutions: 10\% ( $\diamond), 20 \%(\square)$ and 30\% $(\Delta)$.

Besides the phase transition temperatures corresponding to each concentration, DLS provides information regarding the size distribution of the soluble species. At low 
temperatures, a single signal corresponding to small size particles is obtained from the autocorrelation function. The obtained particle radii were ca. $1.5 \mathrm{~nm}$. Once the samples have reached a certain temperature, there is a sudden increase in the calculated particle size (see Supporting Information, Figure S1). This change reflects the presence of species with hydrodynamic radii of hundreds or thousands of nanometers. The particle size of $1.5 \mathrm{~nm}$ corresponds to Pluronic 10R5 unimers. Below the transition temperatures showed in Figure 3, copolymer chains are stable in the aqueous solutions and no aggregates are present. The hydrodynamic radii of the unimers can be calculated from the intrinsic viscosity of the polymer (Eq. 1). The calculated viscometric radius for this reverse Pluronic at $25^{\circ} \mathrm{C}$ is $1.32 \mathrm{~nm}$, a value close to that obtained by DLS measurements.

As deduced from these results, Pluronic 10R5 do not show a tendency to form regular micelles in water. Mortensen et al. studied Pluronic 25R8 $\left(\mathrm{PO}_{15} \mathrm{EO}_{156} \mathrm{PO}_{15}\right)$ and stated that in fact both random and micellar networks are formed in the semidilute region. ${ }^{7,17}$. In contrast, Chu et al. reported the presence of a one-phase micellar region for semidilute solutions of $\mathrm{PO}_{14} \mathrm{EO}_{24} \mathrm{PO}_{14}$ (Pluronic 17R4). ${ }^{13}$ The lengths of the hydrophobic outer blocks are considerably shorter for Pluronic 10R5 (only 8 units), precluding the formation of flower type micelles. Consequently, Pluronic 10R5 must form another type of aggregates such as random or micellar networks. ${ }^{17,18}$ The influence of the architecture of different triblock copolymers in selective solvents has been thoroughly studied in previous works. ${ }^{19-21}$

Phase diagrams obtained by light scattering and direct observation match each other with the exception of the data for $10 \%(\mathrm{w} / \mathrm{w})$, where the visual result is not reliable (as it should be equal to or above the one obtained by light scattering). The determination 
of phase transitions by visual inspection in diluted solutions is a difficult task. Thus, in the dilute region, below $10 \%$, only light scattering experiments were conducted.

As it was mentioned above, the transition between unimers and aggregates corresponds to an abrupt change in the scattered intensity (Figure 4 and, Supporting Information Figure S1 and Table S1), and the particle size of the resulting aggregates can not be calculated. In contrast, for dilute solutions (below $10 \%$ ) an intermediate aggregate is formed. An additional line has been drawn in Figure 3 to encircle the small region showing this particular behavior (labeled as region IIa in Figure 4). The hydrodynamic radii of these aggregates range between 4 and $12 \mathrm{~nm}$ (Figure 5). The radii of these random networks are practically constant until a certain temperature (ca. $40^{\circ} \mathrm{C}$ ) when the scattered intensity suddenly increases indicating the formation of large aggregates (Figure 5). As the random networks grow, along the turbid region II, they reach a point in which they are capable of forming more homogeneous (transparent) micellar networks (region III). In the case of more concentrated solutions (above 50\%) this gradual transition can not be detected probably due to the considerably higher amount of scattering caused by the excess of solute and it occurs in a narrow temperature range. As can be seen in Figure 5, for concentrations below 10\%, a plateau value of the hydrodynamic radii could be measured. This is not the case for the $10 \%$ sample, which can be considered the limit of the semidilute regime for this system. Naskar et al. ${ }^{22}$ have recently reported the phase diagram of dilute aqueous solutions of 10R5. Their phase diagram matches ours from a qualitatively point of view: our "turbid" region in the dilute regime is roughly 10 degrees below their reported micellar zone. A possible explanation for this difference is that they have determined the cloud points by visual detection. Regarding the sizes of aggregates, they reported very small changes in the hydrodynamic diameters for their dilute solutions along the aggregation process. 
Besides the information regarding the size of the species in solution, DLS measurements permit to study the ratio between different size populations in the sample. For the dilute solutions ca. $90 \%$ of the sample (mass \%) correspond to the small aggregates, and there is $10 \%$ of larger aggregates. This percentage grows with the temperature until the smaller aggregates disappear and the sample presents only one size population corresponding to a random network of aggregates. The aggregation numbers calculated from DLS data using a branched polymer model range between 20 and ca. 150 molecules. In contrast, solutions above $10 \%(\mathrm{w} / \mathrm{w})$ do not show this behavior. In these samples, the polymeric chains density is higher and the smaller aggregates can not be detected.

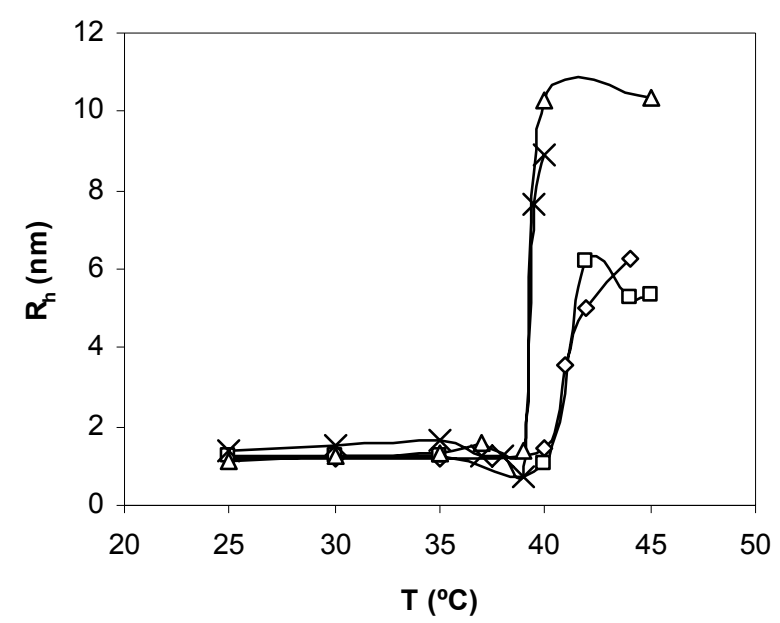

Figure 5. Hydrodynamic radii of Pluronic 10R5 in water as a function of the temperature for dilute solutions: $(\diamond) 3 \%,(\square) 5 \%,(\Delta) 7 \%$ and $(x) 10 \%$.

Viscosity measurements at different temperatures were performed in order to study the phase transitions. Three different solutions of Pluronic 10R5 in water, 20, 30 and $40 \%$ (w/w), were measured (see Supporting Information, Figure S2). More diluted solutions could not been measured because the viscometer sensitivity was not enough to detect viscosity changes. The viscosity of these suspensions decreases as temperature 
increases. This is a typical behavior for a liquid. For the studied samples, the viscosity curves did not show any changes attributable to the phase transitions. If the aggregates are only a small part of the total solved copolymer, their contribution to the viscosity is not significant.

FTIR is sensitive to molecular structural changes so it can be useful to follow the dynamics of poloxamers and poloxamines aggregation as a function of temperature. Some previous works have explored the usefulness of this technique to follow the microphase separations in these systems. ${ }^{23-26}$

There are several vibration modes sensitive to the hydration state surrounding the PPO and PEO blocks. The most indicative modes are the symmetric C-H stretch of methylene groups, located at ca. $2850 \mathrm{~cm}^{-1}$, the C-O-C stretching vibrations of PPO and PEO blocks at ca. $1100 \mathrm{~cm}^{-1}$, and the $\mathrm{CH}_{3}$ symmetric deformation modes at ca. 1380 $\mathrm{cm}^{-1}$. When the PPO and the PEO blocks are bound to water molecules, the C-O band remains at lower wavenumbers. During the aggregation process PPO and PEO tend to dehydrate so the $\mathrm{C}-\mathrm{O}$ band shifts to higher wavenumbers. ${ }^{24}$ 

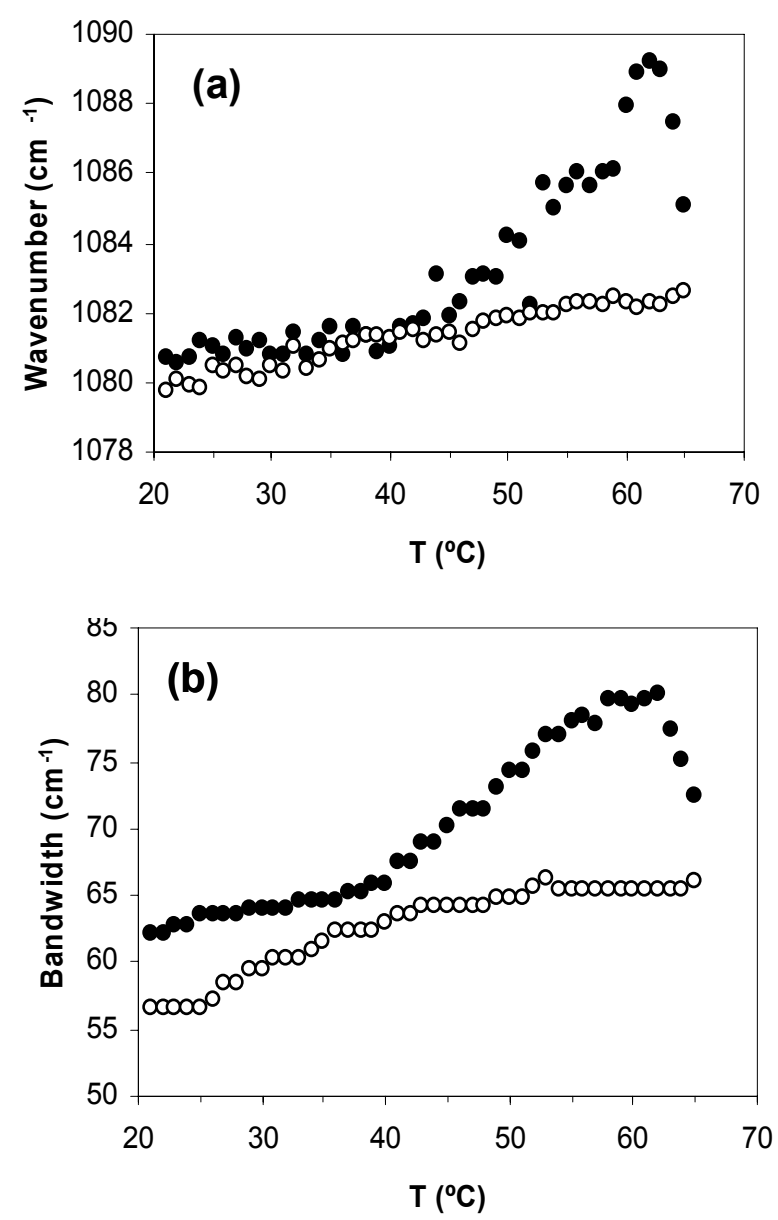

Figure 6. Wavenumber (a) and bandwidth (b) shifts of the C-O stretching vibration band for $10 \%(\bullet)$ and $30 \%(\mathrm{\circ})(\mathrm{w} / \mathrm{w})$ solutions of $10 \mathrm{R} 5$ as a function of the temperature.

Figure 6a shows this shift for the C-O stretching band of two 10R5 aqueous solutions containing $10 \%$ and $30 \%(\mathrm{w} / \mathrm{w})$ of Pluronic, respectively. The curve corresponding to $10 \%$ mixtures presents a cusp at about $38^{\circ} \mathrm{C}$. As stated by the light scattering measurements, at this temperature $10 \%$ solutions of this poloxamer start to aggregate to form random networks. On the other hand, for the $30 \%$ curve, the change at ca. $30{ }^{\circ} \mathrm{C}$ corresponding to the aggregation temperature of this solution is barely perceived. Nevertheless, the bandwidths can also be useful to ascertain the onset of phase transitions. The bandwidth broadening is attributable to a more disordered conformation of the $\mathrm{C}-\mathrm{O}-\mathrm{C}$ skeletons. Figure $6 \mathrm{~b}$ shows that the deviations from the initial baseline 
are observed at approximately the same temperatures registered for the wavenumber shifts. In this case, the shift for the $30 \%$ solution is clearly detected at ca. $27^{\circ} \mathrm{C}$. Finally, a sudden drop is observed at ca. $60{ }^{\circ} \mathrm{C}$ in the case of the $10 \%$ sample. No phase transition can be detected by visual inspection, and the turbidity of this mixture does not change above this point. A higher hydration of the poloxamer above $60{ }^{\circ} \mathrm{C}$ is deduced from the diminishing wavenumber and bandwidth. This could be attributed to a macroscopic aggregation of the phase separated particles.

Tetronic 90R4 + water. The phase diagram of aqueous Tetronic 90R4 (Figure 7) is more complex than that of Pluronic 10R5. There are four zones in the diagram consistent with the different types of aggregates that can be found in this system.

The diagram was also constructed using light scattering data and visual inspection. Both techniques gave practically the same transitions with some deviations, especially at high concentrations. Above $30 \%(\mathrm{w} / \mathrm{w})$, the suspensions could only be measured by direct observation, since the light scattering technique is very sensitive to heterogeneities caused by temperature and viscosity gradients within the sample. As can be seen in Figure 7, there is a solubility limit at ca. $75 \%(\mathrm{w} / \mathrm{w})$ for Tetronic $90 \mathrm{R} 4$ in water. At low temperatures all the studied solutions are clear. For concentrations between 0 and $40 \%$, the suspensions become turbid when the temperature is increased, but this change is not observed for higher 90R4 concentrations. At higher temperatures, those turbid suspensions become clear again, so the phase diagram shows a lenticular region in the semidilute concentration region. Finally, for temperatures above $40^{\circ} \mathrm{C}$ phase separation occurs for all the dispersions. Plestil et al. obtained a phase diagram using small-angle neutron scattering and differential scanning calorimetry ${ }^{7}$ with similar results. 
The scattered intensity/temperature patterns presented in Figure 8 can be correlated with the phase diagram. The peaks correspond to the central zone of the diagram where cloudiness is observed. After these peaks, ca. $40-45{ }^{\circ} \mathrm{C}$, there is a new increase in the scattered intensity corresponding to the onset of the phase separation region (see also Supporting Information, Figure S1).

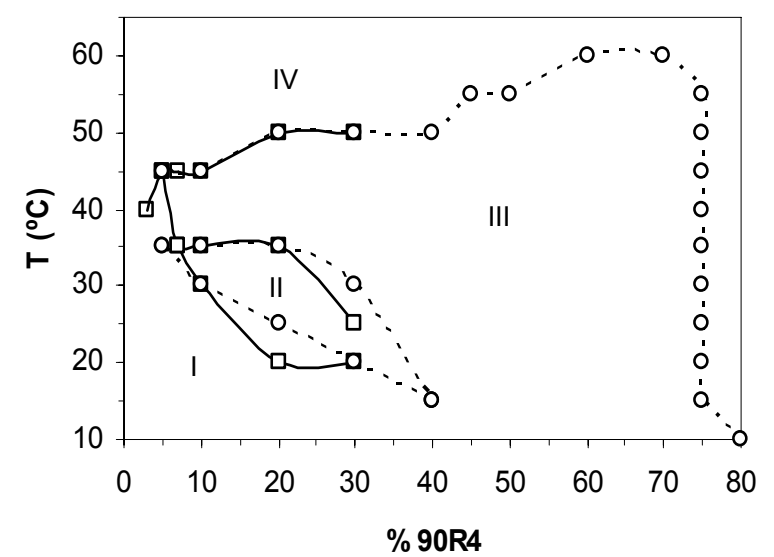

Figure 7. Phase diagram of Tetronic 90R4 in water obtained by ( $\square$ ) DLS and (०) direct observation. Region I: unimers (transparent); region II: random network (turbid); region III: micellar networks (transparent); region IV: macrophase separation (turbid)

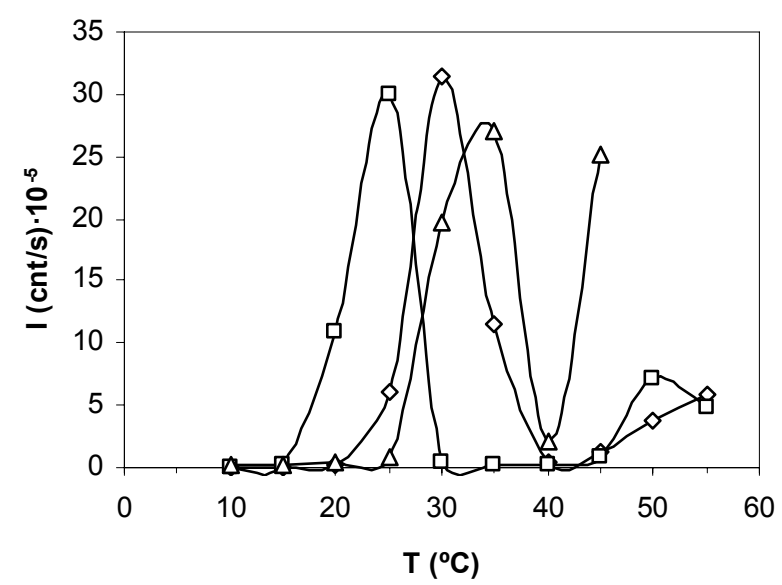

Figure 8. Variations of the scattered intensity (wavelength $852.2 \mathrm{~nm}$; scattering angle $90^{\circ}$ ) for different 90R4 solutions: $10 \%(\Delta), 20 \%(\diamond)$, and 30\% (口) 
In order to characterize the aggregation behavior of $90 \mathrm{R} 4$ in water at different temperatures, DLS was utilized to obtain the hydrodynamic radii of the species in the four phases. At low temperatures, phase I corresponds to unimers. In this region, DLS reported the presence of species with an approximate hydrodynamic radius of $2.2 \mathrm{~nm}$ (Figure 9). This result is consistent with the viscometric radii of the unimers $(2.36 \mathrm{~nm})$ calculated from capillary viscosity data (Eq. 1). In the phase of unimers, solutions present a transparent and homogeneous appearance.

For region II of the phase diagram, the mixtures present turbidity. The PPO blocks start to aggregate at temperatures above $14{ }^{\circ} \mathrm{C}$, when water becomes a poor solvent. ${ }^{27}$ The size distribution obtained by DLS is not reliable at this point because of the excessive amount of light dispersed by these samples. The behavior of 90R4 in this phase is similar to that observed for 10R5, and it can be ascribed to the formation of an inhomogenous random network. ${ }^{7}$

Solutions in region III are clear again and the particle sizes could be measured with the aid of DLS, which reveals that no unimers are present in this phase. These new aggregates show variable hydrodynamic radii that grow as temperature increases (Figure 9). The size continues growing until this process leads the system to a macrophase separation. More concentrated solutions yield larger aggregates, up to 12 $\mathrm{nm}$ for $30 \%$ dispersions. In this region, Plestil et al. ${ }^{7}$ reported that the predominant association species for the same poloxamine were regular micelles. Nevertheless, the size of the aggregates in this region is not uniform, as can be seen in Figure 9. They grow as temperature increases up to the macrophase separation (region IV). This result confirms that the aggregates in this region are micellar networks. Once the macrophase separation is reached, large particles are formed by clustering of the aggregates. 
More diluted solutions do not show the same behavior as those between $7 \%$ and $40 \%$. Solutions below 7\% (w/w) do not present regions II and III (random networks and micellar networks). Only one phase transition is observed by DLS for both $5 \%$ and $3 \%$ solutions. The unimers (size ca. $2 \mathrm{~nm}$ ) do not appreciably grow in size up to the phase separation at about $40^{\circ} \mathrm{C}$ (see Supporting Information, Table S2).

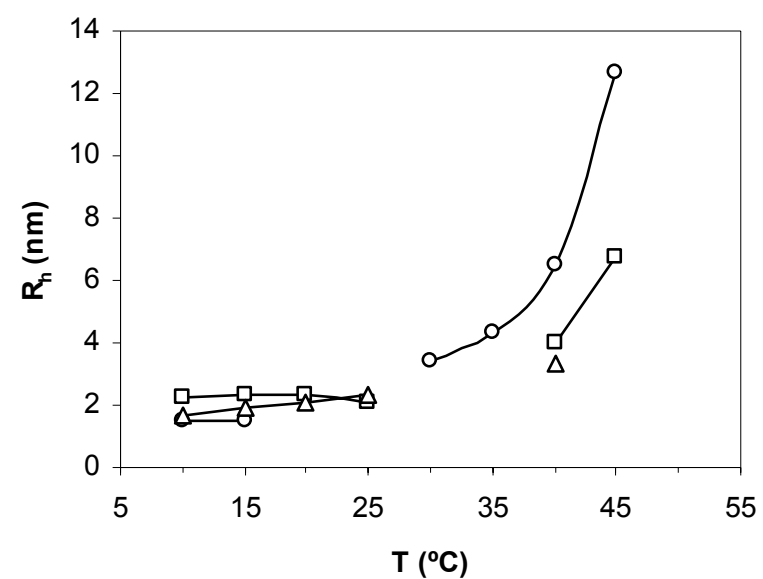

Figure 9. Variation in the hydrodynamic radii as a function of temperature for different Tetronic 90R4 concentrations: $(\circ) 30 \%,(\square) 20 \%,(\Delta) 10 \%$. The central discontinuities are due to phase transitions (see text and Figure 7).

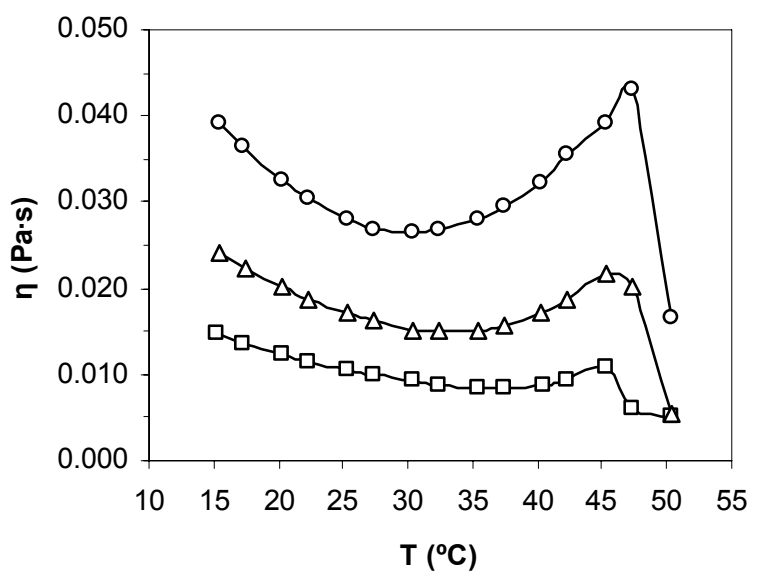

Figure 10. Viscosity curves as a function of the temperature for two different Tetronic 904 concentrations: (०) $30 \%,(\Delta) 25 \%,(\square) 20 \%$. 
Viscosity measurements of Tetronic 90R4 (Figure 10) in the semidilute region show a more complex behavior with temperature than that of Pluronic 10R5. In the first part of the curves the viscosities diminish until they reach a minimum. These decreases correspond to regions I and II of the phase diagram, i.e. unimers and random networks (Figure 7). As occurs in the case of Pluronic 10R5, no changes in the trend of the curves are detected through the unimer-random network transition. As mentioned above, rotational viscometry can not detect these transitions between regions I and II because it is not sensitive enough. The minima in the viscosities of the studied mixtures correspond to the transitions between regions II and III. Above these transition temperatures, the viscosities rise again as the micellar networks are being formed, finally reaching a maximum. These maxima (between 45 and $47^{\circ} \mathrm{C}$ ) are located at the macrophase separation temperatures of the respective mixtures. Then, there is a sudden drop of the viscosities along the last region of the phase diagrams.

The raise observed along region III counteracts the typical viscosity decrease with temperature. We have also plotted the relative viscosities as a function of the temperature (see Supporting Information, Figure S2). It is clearly shown that the relative viscosity for these solutions is practically constant until an onset temperature is reached. From that point, a remarkable increase is registered in region III. For this open association phase, the aggregate size is continuously increasing. Once the aggregates are large enough they collapse in the form of macroscopic particles that can settle down during the phase separation stage. A previously studied direct poloxamine, Tetronic 908, showed also a complex viscosity behavior. ${ }^{28}$ For this block copolymer, the increase of the volume fraction of micelles subsequently induces a rise in viscosity. Then, the viscosity also shows a maximum, but in this case, the fall is due to the fact that the volume fraction of micelles goes through a maximum. 

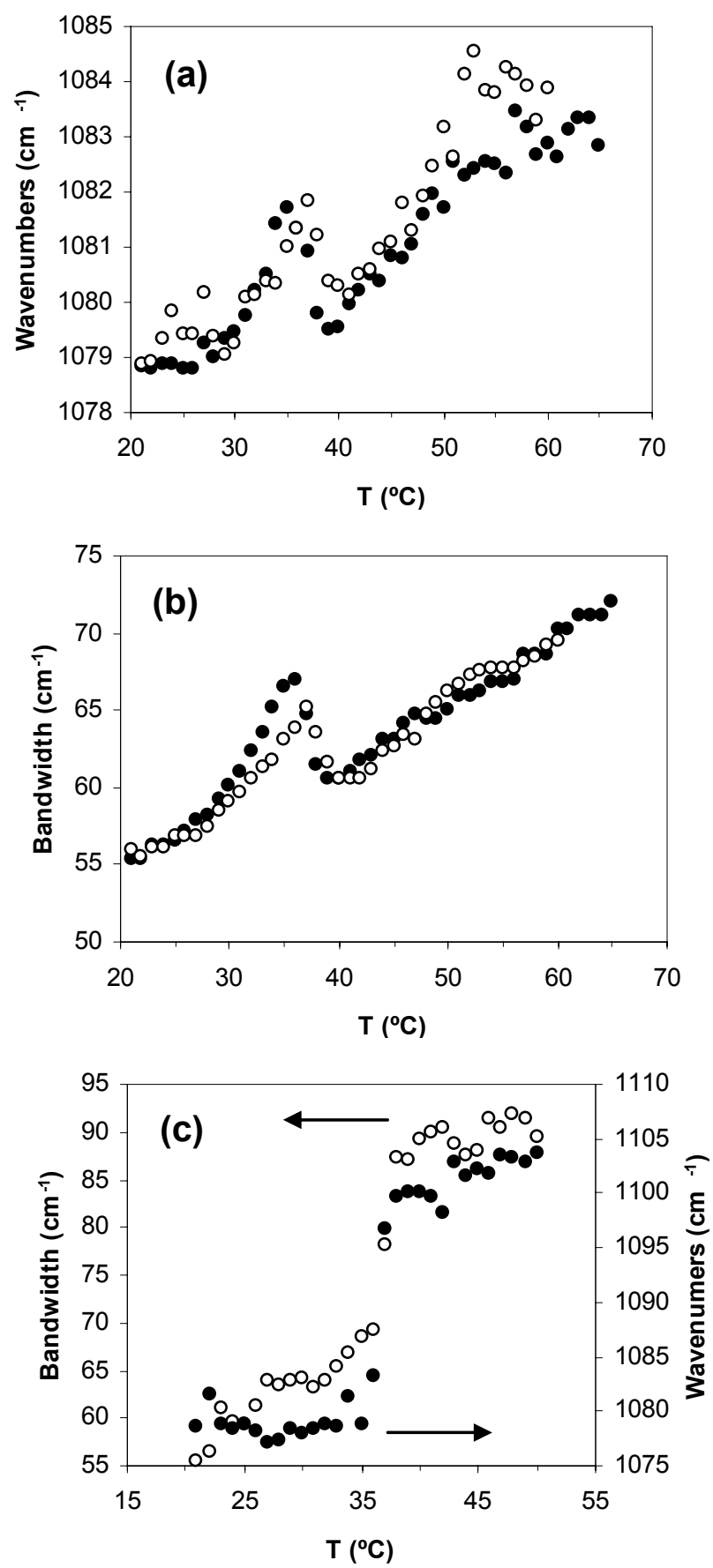

Figure 11. Wavenumber shift of the C-O stretching vibration band for $15 \%(\bullet)$ and $10 \%(\circ)$ 90R4 solutions as a function of the temperature (a). Bandwidth shifts for $15 \%(\bullet)$ and $10 \%(\circ)$ 90R4 solutions (b). Wavenumber (•) and bandwidth (०) shifts for 5\% (w/w) 90R4 solutions (c).

Figure 11 shows the shift of the $\mathrm{C}-\mathrm{O}$ stretching band and the corresponding bandwidth for three different 90R4 solutions. The curves are more complex than those of 10R5. The $10 \%$ and $15 \%(\mathrm{w} / \mathrm{w})$ curves appear to be quite similar. They present a peak between 
28 and $38{ }^{\circ} \mathrm{C}$ (for the $15 \%$ sample) with a maximum located at about $35^{\circ} \mathrm{C}$ followed by a large increase both in wavenumber shift and bandwidth. The onset of the first peak corresponds to the transition between unimers and random networks in the same way as occurred for Pluronic 10R5 (see above). The peak maximum at $35{ }^{\circ} \mathrm{C}$ marks the transition between regions II (random networks) and III (micellar networks). The infrared shifts allow us to deduce that, after this transition PPO and PEO chains are in a more hydrated microenvironment. This can be attributed to the end of the microphase separation (turbidity of region II). As can be noticed, the minimum found at about $38{ }^{\circ} \mathrm{C}$ do not correspond to the last phase transition between regions III and IV (ca. $48{ }^{\circ} \mathrm{C}$ for this mixture). FTIR cannot detect the macrophase separation because this technique gives information at a molecular scale. The minimum in the $\mathrm{C}-\mathrm{O}$ wavenumber would indicate a change in the hydration state of the micellar networks. The system reaches a point in which the micellar networks start to expel the excess water. At higher temperatures, the system becomes unstable, and a macrophase separation takes place. As can be seen in Figure 11a, the second maximum, corresponding to the micellar networks, is considerably higher (i.e. less hydrated) than the first (random networks).

On the other hand, the curve for a dilute $90 \mathrm{R} 4$ solution, $5 \%(\mathrm{w} / \mathrm{w})$, is different from those shown above. An abrupt and large increase in the C-O vibration wavenumber (and bandwidth) at about $37^{\circ} \mathrm{C}$ is observed. As previously stated, samples with less than $7 \%$ of 90R4 do not present neither the random network nor the micellar network phases. Thus, the only phase transition between unimers (region I) and the macrophase separation (region IV) is reflected in the large shifts shown in the $5 \%$ curve (Figure 11b). 
Table 1. Hydrodynamic radii for $20 \%$ aqueous $90 \mathrm{R} 4$ in different media as a function of the temperature. Blanks correspond to turbid regions where radii cannot be given (regions II and IV of the phase diagram).

\begin{tabular}{lllll}
\hline $\mathbf{T}\left({ }^{\circ} \mathbf{C}\right)$ & $\mathbf{H}_{\mathbf{2}} \mathbf{O}$ & $\mathbf{H C l} \mathbf{0 . 1 M}$ & $\mathbf{N a C l ~ 0 . 1 M}$ & $\mathbf{N a O H ~ 0 . 1 M}$ \\
\cline { 2 - 5 } & $\left.\mathbf{R}_{\mathbf{h}} \mathbf{( n m}\right)$ & $\mathbf{R}_{\mathbf{h}}(\mathbf{n m})$ & $\mathbf{R}_{\mathbf{h}}(\mathbf{n m})$ & $\mathbf{R}_{\mathbf{h}}(\mathbf{n m})$ \\
\hline 10 & 2.26 & 1.50 & 1.79 & 2.51 \\
15 & 2.29 & 1.50 & 1.74 & 2.72 \\
20 & 2.36 & - & - & - \\
25 & 2.12 & - & - & - \\
30 & - & - & - & 7.84 \\
35 & - & - & 4.32 & 10.64 \\
40 & 3.99 & 3.97 & 7.01 & - \\
45 & 6.77 & 6.49 & - & - \\
50 & - & 5.92 & - & - \\
\hline
\end{tabular}

Influence of $\mathrm{pH}$ and ionic strength. Poloxamine copolymers possess two tertiary amine central groups that provide sensitivity to the $\mathrm{pH}$, so they cannot be strictly considered as non-ionic surfactants. The two $\mathrm{pK}_{\mathrm{a}}$ values $(4.34$ and 8.15$)$ for Tetronic $90 \mathrm{R} 4$ were obtained by potentiometric titration (see Supplementary information, Figure S3). Some authors have studied the effect of $\mathrm{pH}$ on the associative behavior of several Tetronics. ${ }^{8,29-31}$. With the aim of studying the behavior of Tetronic $90 \mathrm{R} 4$ solutions as a function of $\mathrm{pH}$ and/or ionic strength, dynamic light scattering was used. Table 1 shows the hydrodynamic radii obtained for a semidilute solution of $90 \mathrm{R} 4(20 \% \mathrm{w} / \mathrm{w})$ in different media. These data are consistent with the phase diagrams obtained by direct observation (see Supplementary Information, Figure S4). As can be seen, the aggregation process corresponding to the formation of random networks (i.e. the onset of turbidity) starts between 15 and $20^{\circ} \mathrm{C}$ for $\mathrm{HCl}, \mathrm{NaCl}$ and $\mathrm{NaOH}$, while for water, as it was studied above, it occurs at significantly higher temperatures (between 25 and 30 $\left.{ }^{\circ} \mathrm{C}\right)$. On the other hand, the apparition of species with a higher hydrodynamic radius (micellar aggregates in region III) occurs at lower temperatures for $\mathrm{NaCl}$ and $\mathrm{NaOH}$ 
media than for $\mathrm{HCl}$ or water. Two effects have to be considered in order to analyze these results: on the one hand, the protonation of the Tetronic amine groups that occurs at low $\mathrm{pH}$ values and, on the other hand, the influence of the ions on the conformation of the copolymer blocks. The tendency to aggregate at lower temperatures for $\mathrm{NaCl}$ media is attributable to the effect of the $\mathrm{Na}^{+}$and $\mathrm{Cl}^{-}$ions. In fact, Liu et al. have pointed that these two ions cause the largest decreases of the cloud points for the studied cations and anions due to a salting-out effect. ${ }^{23}$ Besides this effect on the aggregation temperature, the unimer size is remarkably lower in $\mathrm{NaCl}$ and $\mathrm{HCl}$ solutions than in pure water. In the case of $\mathrm{NaOH}$ solutions, there are two effects to be considered: a lower transition temperature between regions II and III than that in $\mathrm{NaCl}$ and a small change in the unimer size. Having both the $\mathrm{Na}^{+}$cation in common, it seems clear that $\mathrm{Cl}^{-}$and $\mathrm{OH}^{-}$are responsible for these differences. The effect of anions in the unimer size is stronger than that of cations. Regarding the protonation of the Tetronic amine groups, both nitrogen atoms must be charged in $\mathrm{HCl} 0.1 \mathrm{M}$. Some authors have suggested that this hinders the formation of poloxamine micelles and aggregates. ${ }^{8}$ In direct Tetronic molecules, the central moiety containing the charged amine groups is located close to the inner hydrophobic blocks. These central portions form the core of the micelles in water solutions. If this region is charged, repulsive forces between different molecules will appear, so the formation of the aggregates is prevented. This is not the case for reverse Tetronics, where the hydrophobic blocks are situated in the outer portions, far from the charged moieties. As can be seen in Table 1, the particle sizes in region III between 40 and $45^{\circ} \mathrm{C}$ (micellar aggregates) are practically the same for $\mathrm{HCl}$ and water. 


\section{CONCLUSIONS}

Using the data obtained from light scattering and direct observation, the phase diagrams were obtained for the studied range of concentrations and temperatures. The phase diagram of aqueous Pluronic 10R5 presents three regions while that of Tetronic 90R4 shows four regions. Despite their different structures, the phase diagrams of both copolymers share two regions, those corresponding to unimers and random network aggregates. These block copolymers do not show a tendency to form regular micelles due to their reverse-type structures with insoluble outer blocks. Closed association aggregates are found for PEO-PPO-PEO block copolymers in water. In contrast, reverse type Pluronics or Tetronics do not easily form regular micelles. When the block sizes are appropriate, flower type micelles are formed, and this can be the case for some reverse Pluronics (PPO-PEO-PPO). Otherwise, open association aggregates (such as random networks or micellar networks) are observed. The reduced ability to form regular micelles has been attributed to the entropy loss associated with the looping of the middle block. The reverse triblock copolymers have a strong tendency to form structures by sharing one molecule by two micellar cores. This is also the case for reverse Tetronics, given their special architecture.

It has been proved that all the phase transitions observed by light scattering and visual inspection can be corroborated with the aid of two complementary techniques: FTIR and rotational viscometry. The latter can not provide information regarding the transition between unimers and random networks and the former does not show a clear change in the macrophase separation corresponding to Tetronic 90R4 but, by combining both, all the phase transitions can be registered. Therefore, FTIR and rotational viscometry can complement DLS measurements in surfactants aggregation studies. 


\section{ACKNOWLEDGEMENTS}

The authors acknowledge the financial aid from the Ministerio de Ciencia e Innovación (project MAT2007-65752). E.L. thanks for a Gobierno de Navarra grant (Plan de Formación y de I+D). We are also grateful to Prof. G. Tardajos (Universidad Complutense) for her help with the NMR measurements.

\section{SUPPORTING INFORMATION}

Figures S1-S4 and Tables S1-S2. This material is available free of charge via the Internet at http://pubs.acs.org/

\section{REFERENCES}

(1) Schmolka, I. Review of Block Polymer Surfactants. J. Am. Oil Chem. Soc. 1977, 54, $110-116$.

(2) Alexandridis, P.; Alan Hatton, T. Poly(Ethylene Oxide)-Poly(Propylene Oxide)Poly(Ethylene Oxide) Block Copolymer Surfactants in Aqueous Solutions and at Interfaces: Thermodynamics, Structure, Dynamics, and Modeling. Colloids Surf. Physicochem. Eng. Aspects 1995, 96, 1-46.

(3) Pham Trong, L. C.; Djabourov, M.; Ponton, A. Mechanisms of Micellization and Rheology of PEO-PPO-PEO Triblock Copolymers with various Architectures. $J$. Colloid Interface Sci. 2008, 328, 278-287.

(4) Wang, Q.; Li, L.; Jiang, S. Effects of a PPO-PEO-PPO Triblock Copolymer on Micellization and Gelation of a PEO-PPO-PEO Triblock Copolymer in Aqueous Solution. Langmuir 2005, 21, 9068-9075. 
(5) Jiang, R.; Jin, Q.; Li, B.; Ding, D.; Shi, A. Phase Diagram of Poly(Ethylene Oxide) and Poly(Propylene Oxide) Triblock Copolymers in Aqueous Solutions. Macromolecules 2006, 39, 5891-5896.

(6) Lazzara, G.; Milioto, S.; Gradzielski, M. The Solubilisation Behaviour of some Dichloroalkanes in Aqueous Solutions of PEO-PPO-PEO Triblock Copolymers: A Dynamic Light Scattering, Fluorescence Spectroscopy, and SANS Study. Phys. Chem. Chem. Phys. 2006, 8, 2299-2312.

(7) Plestil, J.; Pospisil, H.; Sikora, A.; Krakovsky, I.; Kuklin, A. Small-Angle Neutron Scattering and Differential Scanning Calorimetry Study of Associative Behaviour of Branched Poly(Ethylene Oxide)/poly(Propylene Oxide) Copolymer in Aqueous Solution. Journal of applied crystallography 2003, 36, 970-975.

(8) Gonzalez-Lopez, J.; Alvarez-Lorenzo, C.; Taboada, P.; Sosnik, A.; Sandez-Macho, I.; Concheiro, A. Self-Associative Behavior and Drug-Solubilizing Ability of Poloxamine (Tetronic) Block Copolymers. Langmuir 2008, 24, 10688-10697.

(9) Ooya, T.; Park, K. in Polymer solution properties, micelles, dendrimers, and hydrogels. Mahato, R. I., Ed.; Biomaterials for delivery and targeting of proteins and nucleic acids; CRC Press: 2005.

(10) Mortensen, K.; Brown, W. Poly(Ethylene Oxide)-Poly(Propylene Oxide)Poly(Ethylene Oxide) Triblock Copolymers in Aqueous Solution. the Influence of Relative Block Size. Macromolecules 1993, 26, 4128-4135.

(11) Mortensen, K.; Pedersen, J. S. Structural Study on the Micelle Formation of Poly(Ethylene Oxide)-Poly(Propylene Oxide)-Poly(Ethylene Oxide) Triblock Copolymer in Aqueous Solution. Macromolecules 1993, 26, 805-812. 
(12) Wanka, G.; Hoffmann, H.; Ulbricht, W. Phase Diagrams and Aggregation Behavior of Poly(Oxyethylene)-Poly(Oxypropylene)-Poly(Oxyethylene) Triblock Copolymers in Aqueous Solutions. Macromolecules 1994, 27, 4145-4159.

(13) Zhou, Z.; Chu, B. Phase Behavior and Association Properties of Poly(Oxypropylene)-Poly(Oxyethylene)-Poly(Oxypropylene) Triblock Copolymer in Aqueous Solution. Macromolecules 1994, 27, 2025-2033.

(14) Hubbard, A.; Somasundaran, P., Eds.; In Encyclopedia of Surface and Colloid Science; Pivovarov, S., Ed.; Taylor \& Francis: New York, 2006; , pp 4617-4642.

(15) Mortensen, K. Cubic Phase in a Connected Micellar Network of Poly(Propylene Oxide)-Poly(Ethylene Oxide)-Poly(Propylene Oxide) Triblock Copolymers in Water. Macromolecules 1997, 30, 503-507.

(16) Nijenhuis, K. Thermoreversible Networks - Viscoelastic Properties and Structure of Gels - Introduction. Advances in Polymer Science 1997, 130, 1-12.

(17) Mortensen, K.; Brown, W.; Jorgensen, E. Phase-Behavior of Poly(Propylene Oxide) Poly(Ethylene Oxide) Triblock Copolymer Melt and Aqueous-Solutions. Macromolecules 1994, 27, 5654-5666.

(18) Liu, T.; Liu, L.-Z.; Chu, B. in Amphiphilic Block Copolymers: Self-Assembly and Applications. Alexandridis, P.; Lindman, B., Ed.; Elsevier Science: 2000.

(19) TenBrinke, G.; Hadziioannou, G. Topological Constraints and their Influence on the Properties of Synthetic Macromolecular Systems .2. Micelle Formation of Triblock Copolymers. Macromolecules 1987, 20, 486-489.

(20) Plestil, J.; Hlavata, D.; Hrouz, J.; Tuzar, Z. Dilute and Semidilute Solutions of ABA Block Copolymer in Solvents Selective for A-Block Or B-Block .1. SmallAngle X-Ray-Scattering Study. Polymer 1990, 31, 2112-2117. 
(21) Raspaud, E.; Lairez, D.; Adam, M.; Carton, J. Triblock Copolymers in a Selective Solvent .1. Aggregation Process in Dilute-Solution. Macromolecules 1994, 27, 2956-2964.

(22) Naskar, B.; Ghosh, S.; Moulik, S. Solution Behavior of Normal and Reverse Triblock Copolymers (Pluronic L44 and 10R5) Individually and in Binary Mixture. Langmuir 2012, 28, 7134-46.

(23) Zheng, L.; Guo, C.; Wang, J.; Liang, X.; Bahadur, P.; Chen, S. Micellization of Pluronic L64 in Salt Solution by FTIR Spectroscopy. Vibrational spectroscopy 2005, 39, 157-162.

(24) Guo, C.; Liu, H.; Chen, J. A Fourier Transform Infrared Study of the Phase Transition in Aqueous Solutions of Ethylene Oxide-Propylene Oxide Triblock Copolymer. Colloid Polym. Sci. 1999, 277, 376-381.

(25) Kadam, Y.; Singh, K.; Marangoni, D.; Ma, J.; Aswal, V.; Bahadur, P. Thermodynamic of Micelle Formation of Nonlinear Block Co-Polymer Tetronic (R) T904 in Aqueous Salt Solution. Colloids and surfaces.A, Physicochemical and engineering aspects 2010, 369, 121-127.

(26) Su, Y.; Liu, H.; Wang, J.; Chen, J. Study of Salt Effects on the Micellization of PEO-PPO-PEO Block Copolymer in Aqueous Solution by FTIR Spectroscopy. Langmuir 2002, 18, 865-871.

(27) Glatter, O.; Scherf, G.; Schillen, K.; Brown, W. Characterization of a Poly(Ethylene Oxide) Poly(Propylene Oxide) Triblock Copolymer (EO(27)-PO39EO(27)) in Aqueous-Solution. Macromolecules 1994, 27, 6046-6054.

(28) Perreur, C.; Habas, J.; Peyrelasse, J.; François, J. Rheological and Small-Angle Neutron Scattering Studies of Aqueous Solutions of Branched PEO-PPO-PEO 
Copolymers. Physical review E, Statistical physics, plasmas, fluids, and related interdisciplinary topics 2001, 63.

(29) Alvarez-Lorenzo, C.; Gonzalez-Lopez, J.; Fernandez-Tarrio, M.; Sandez-Macho, I.; Concheiro, A. Tetronic Micellization, Gelation and Drug Solubilization: Influence of $\mathrm{pH}$ and Ionic Strength. European Journal of Pharmaceutics and Biopharmaceutics 2007, 66, 244-252.

(30) Armstrong, J.; Chowdhry, B.; Snowden, M.; Dong, J.; Leharne, S. The Effect of $\mathrm{pH}$ and Concentration upon Aggregation Transitions in Aqueous Solutions of Poloxamine T701. Int. J. Pharm. 2001, 229, 57-66.

(31) Ganguly, R.; Kadam, Y.; Choudhury, N.; Aswal, V. K.; Bahadur, P. Growth and Interaction of the Tetronic 904 Micelles in Aqueous Alkaline Solutions. Journal of Physical Chemistry B 2011, 115, 3425-33. 


\section{Table of Contents Graphic}

Manuscript title: Phase behavior of reverse poloxamers and poloxamines in water Authors: Eneko Larrañeta, José Ramón Isasi

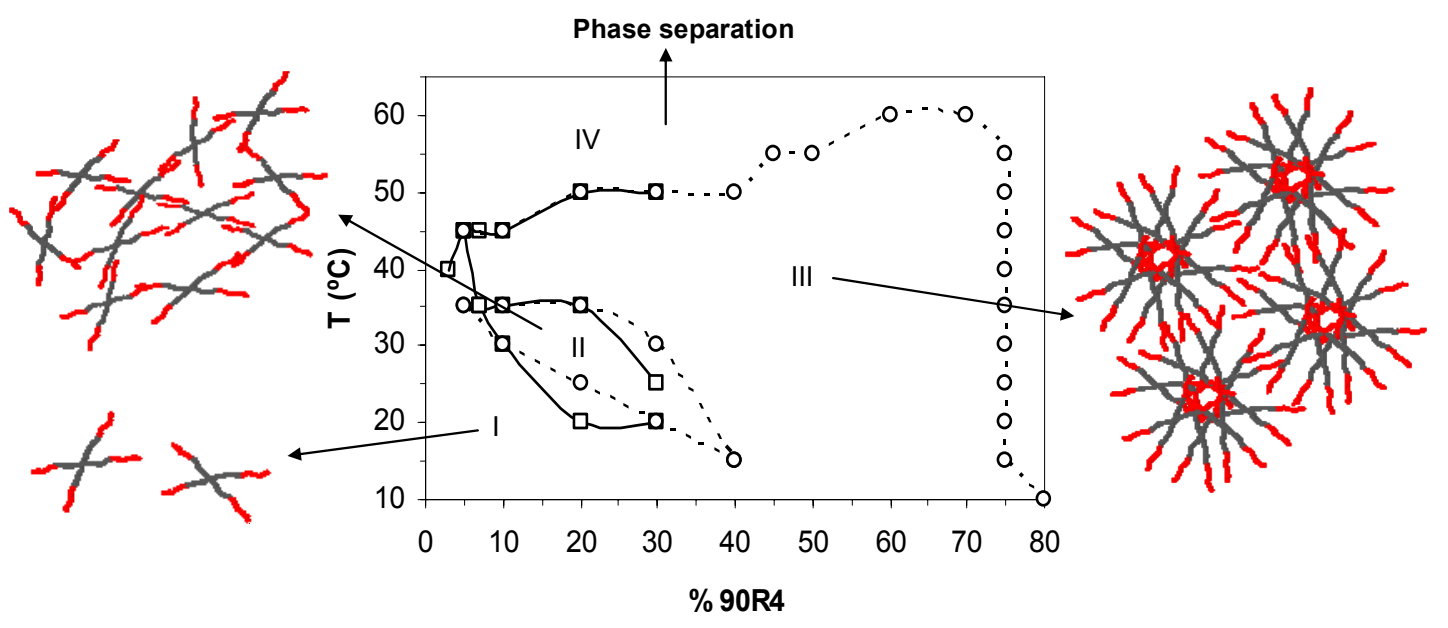




\section{SUPPORTING INFORMATION}

Manuscript title:Phase behavior of reverse poloxamers and poloxamines in water Authors:Eneko Larrañeta, José Ramón Isasi

Table S1.Hydrodynamic radii for $20 \%$ and $30 \% 10$ R5 aqueous solutions as a function of the temperature. Blanks correspond to turbid regions where radii cannot be given (regions II and IV of the phase diagram).

\begin{tabular}{ccc}
\hline & $20 \% 10 \mathrm{R} 5$ & $30 \% 10 \mathrm{R} 5$ \\
\cline { 2 - 3 } $\mathrm{T} /{ }^{\circ} \mathrm{C}$ & $\mathrm{R}_{\mathrm{h}} / \mathrm{nm}$ & $\mathrm{R}_{\mathrm{h}} / \mathrm{nm}$ \\
\hline 25 & 1.50 & 1.38 \\
30 & 1.50 & -
\end{tabular}

Table S2.Hydrodynamic radii for 3\% and 5\% 90R4 aqueous solutions as a function of the temperature. Blanks correspond to turbid regions where radii cannot be given (regions II and IV of the phase diagram).

\begin{tabular}{ccc}
\hline & $3 \% 90 \mathrm{R} 4$ & $5 \% 90 \mathrm{R} 4$ \\
\cline { 2 - 3 } $\mathrm{T} /{ }^{\circ} \mathrm{C}$ & $\mathrm{R}_{\mathrm{h}} / \mathrm{nm}$ & $\mathrm{R}_{\mathrm{h}} / \mathrm{nm}$ \\
\hline 10 & 2.26 & 2.04 \\
15 & 2.29 & 2.07 \\
20 & 2.36 & 2.22 \\
25 & 2.12 & 2.29 \\
30 & 2.24 & 2.48 \\
35 & 2.02 & 2.02 \\
40 & - & 2.78 \\
\hline
\end{tabular}



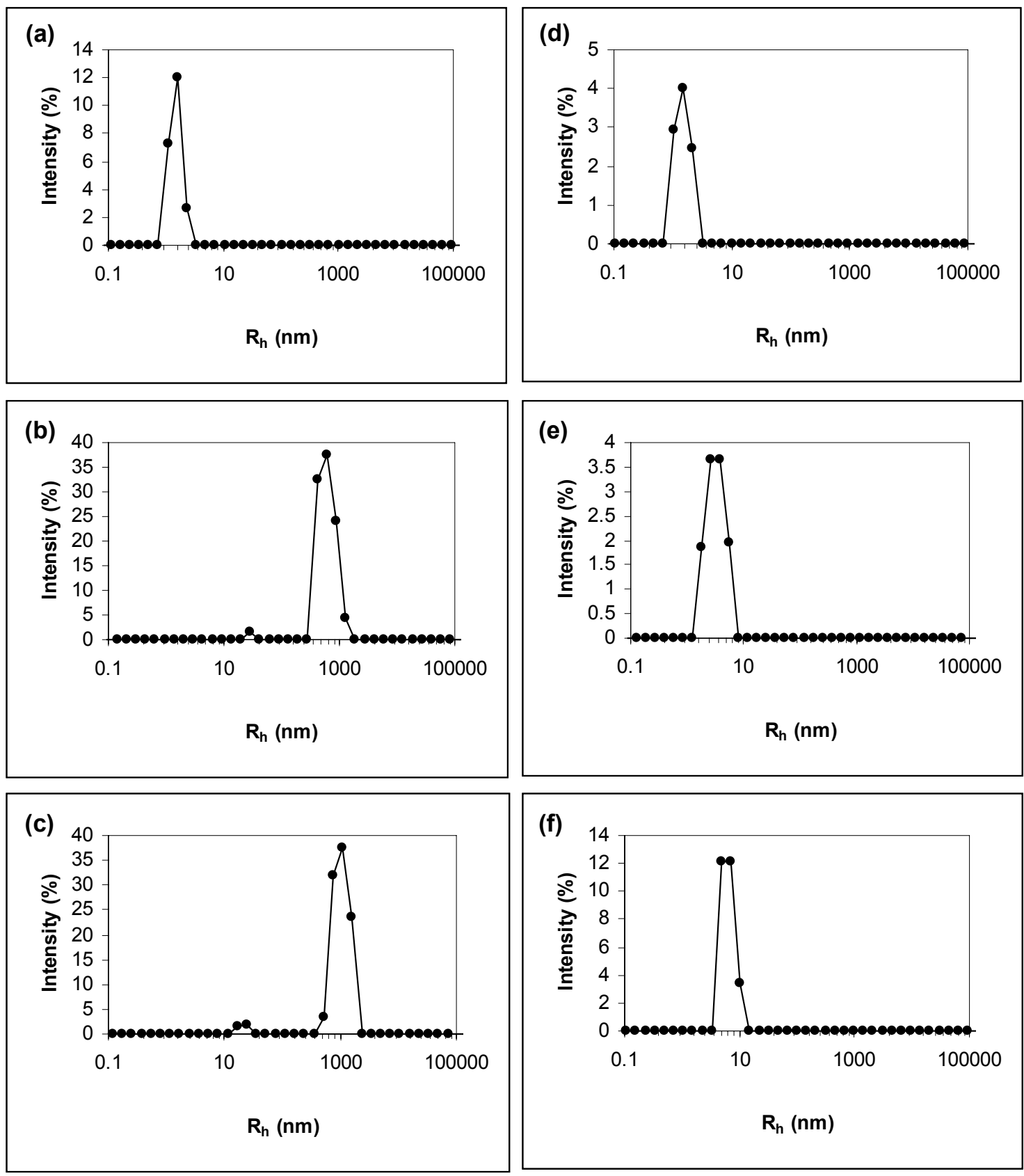

Figure S1.DLS results for: $10 \mathrm{R} 5 / \mathrm{H}_{2} \mathrm{O} 20 \%(\mathrm{w} / \mathrm{w})$ at $25^{\circ} \mathrm{C}(\mathrm{a}) ; 35^{\circ} \mathrm{C}(\mathrm{b}) ; 45^{\circ} \mathrm{C}$ (c); and 90R4/ $\mathrm{H}_{2} \mathrm{O} 30 \%(\mathrm{w} / \mathrm{w})$ measured at $10^{\circ} \mathrm{C}(\mathrm{d}) ; 30^{\circ} \mathrm{C}(\mathrm{e})$; and $40^{\circ} \mathrm{C}(\mathrm{f})$. 
(a)

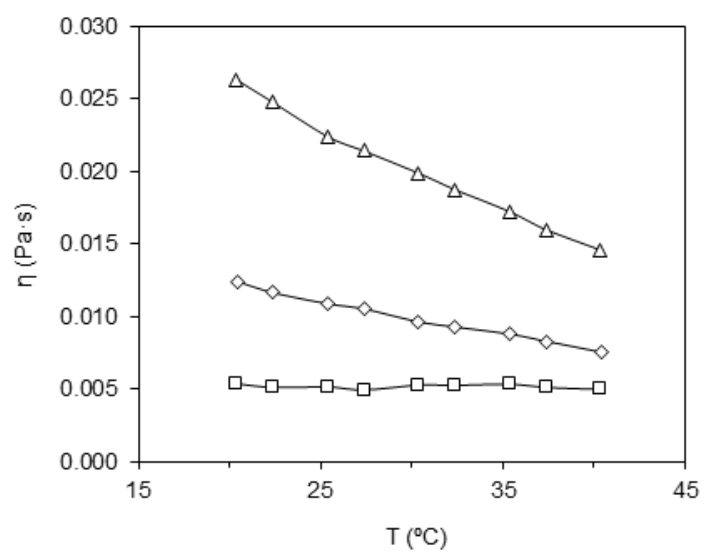

(r)

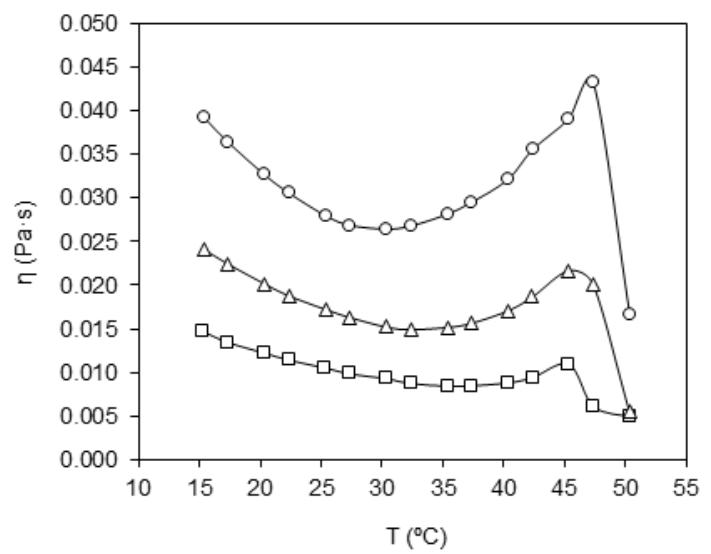

(b)

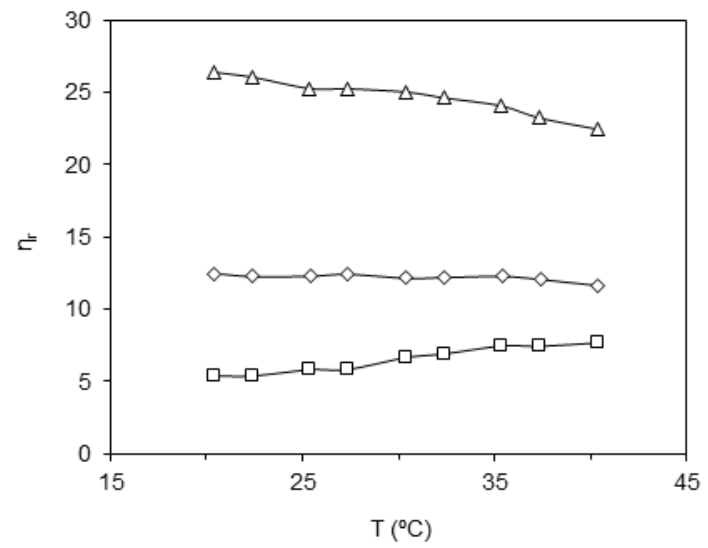

(d)

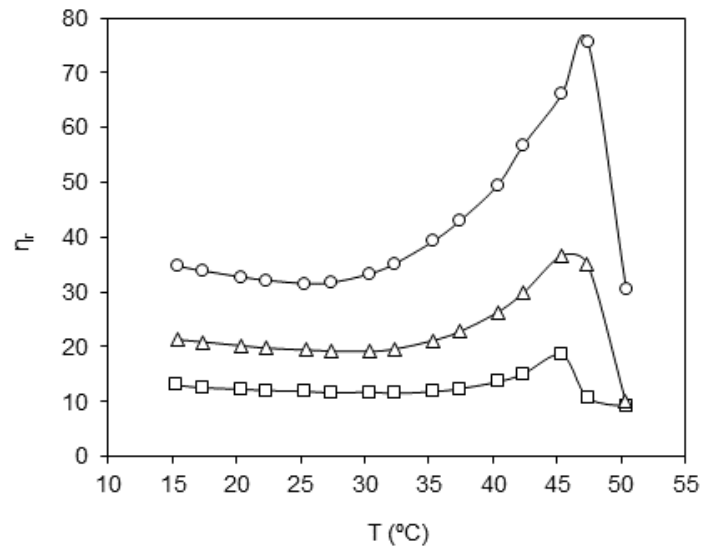

Figure S2.(a)Viscosity and (b) relative viscosity curves as a function of the temperature for three different Pluronic 10R5concentrations: $(\Delta) 40 \%$, (०) 30\%, (口) 20\%.(c)Viscosity and (d) relative viscosity curves as a function of the temperature for two different Tetronic 904 concentrations: $(\circ) 30 \%,(\Delta) 25 \%,(\square) 20 \%$. The values for the viscosity of water were interpolated using the Andrade equation (Glasstone, S.; Laidler, K. J.; Eyring, H. The theory of rate processes: the kinetics of chemical reactions, viscosity, diffusion and electrochemical phenomena; McGraw-Hill: 1941.) 


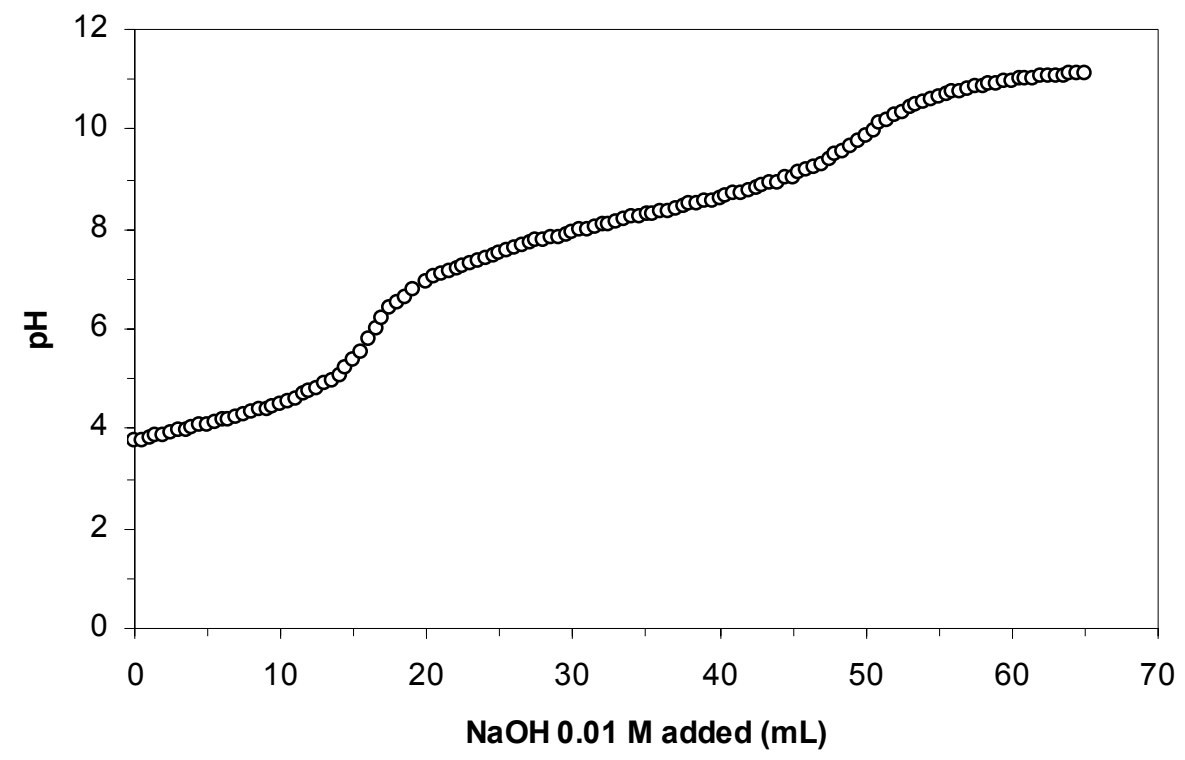

Figure S3. Potentiometric titration curve obtained for Tetronic 90R4 using a CRISON pH \& ION meter GLP 22+. Hydrochloric acid (40 mL $0.01 \mathrm{M})$ was added to Tetronic solutions $(25 \mathrm{~mL} 0.01 \mathrm{M})$. This solution was titrated with $\mathrm{NaOH}(0.01 \mathrm{M})$. 

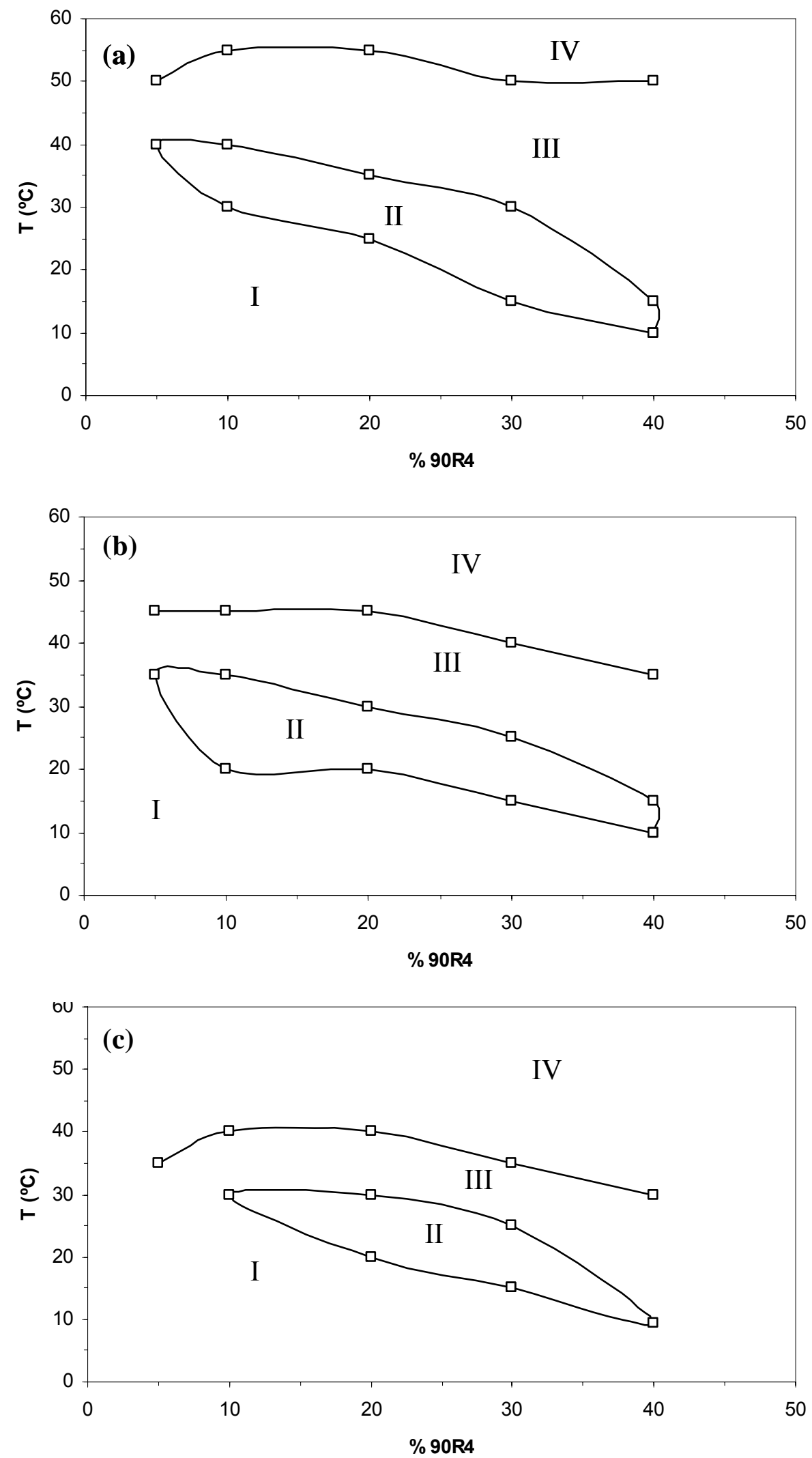

Figure S4. Phase diagrams of Tetronic 90R4 obtained by direct observation in different media: $\mathrm{HCl} 0.1 \mathrm{M}(\mathrm{a}), \mathrm{NaCl} 0.1 \mathrm{M}(\mathrm{b}), \mathrm{NaOH} 0.1 \mathrm{M}$ (c). 